\title{
Структура, состав и свойства кремния, имплантированного ионами цинка и кислорода при повышенной температуре
}

\author{
() В.В. Привезенцев 1,2 , А.П. Сергеев ${ }^{1}$, В.С. Куликаускас ${ }^{3}$, Д.А. Киселев ${ }^{4}$, \\ А.Ю. Трифонов ${ }^{5,6}$, А.Н. Терещенко \\ ${ }^{1}$ Федеральное государственное учреждение „Федеральный научный центр \\ Научно-исследовательский институт системных исследований Российской академии наук“, \\ 117218 Москва, Россия \\ ${ }^{2}$ Физико-технологический институт им. К.А. Валиева Российской академии наук, \\ 117218 Москва, Россия \\ ${ }^{3}$ Научно-исследовательский институт ядерной фризики \\ Московского государственного университета им. М.В. Ломоносова, \\ 119991 Москва Россия \\ ${ }^{4}$ Национальный исследовательский технологический университет „Московский институт стали и сплавов“, \\ 119049 Москва, Россия \\ ${ }^{5}$ Национальный исследовательский университет „МИЭТ“ - Московский институт электронной техники, \\ 124432 Москва, Зеленоград, Россия \\ ${ }^{6}$ Научно-исследовательский институт фризических проблем, \\ 124432 Москва, Зеленоград, Россия \\ ${ }^{7}$ Федеральное государственное бюджетное учреждение науки \\ Институт физики твердого тела Российской академии наук, \\ 142432 Черноголовка, Московская обл., Россия \\ E-mail: v.privezentsev@mail.ru
}

Поступила в Редакцию 5 августа 2020 г.

В окончательной редакции 15 августа 2020 г.

Принята к публикации 15 августа 2020 г.

Подложки $\mathrm{Si}$, выращенные методом Чохральского (n-тип, ориентация (100)), были подвергнуты двойной имплантации: вначале ионами ${ }^{64} \mathrm{Zn}^{+}$с дозой $5 \cdot 10^{16} \mathrm{~cm}^{-2}$ и энергией $50 \mathrm{\kappa э} \mathrm{B}$, а затем ионами ${ }^{16} \mathrm{O}^{+}$с дозой $2 \cdot 10^{17} \mathrm{~cm}^{-2}$ и энергией 20 кэВ. Во время имплантации температура подложки поддерживалась $\sim 350^{\circ} \mathrm{C}$. После имплантации Si-подложка содержит радиационные дефекты и их кластеры: двойники, дислокации, а также нанокластыры (НК), а, именно, на поверхности и в приповерхностном слое подложки образовались $\mathrm{Zn}$-содержащие НК со средним радиусом 10-50 нм преимущественно из фазы металлического $\mathrm{Zn}$ и частично из фазы ZnO. После фотонного отжига до эффективной температуры $700^{\circ} \mathrm{C}$, оптимальной для получения фазы $\mathrm{ZnO}$, радиационные дефекты отожглись, а на поверхности образца зафиксированы $\mathrm{Zn}$-содержащие НК, предположительно, состоящие из фазы $\mathrm{ZnO}$ и частично из фазы $\mathrm{Zn}_{2} \mathrm{SiO}_{4}$ со средним диаметром 50-100нм.

Ключевые слова: кремниевая подложка, цинк, кислород, горячая имплантация, наночастицы, ZnO.

DOI: $10.21883 /$ FTP.2020.12.50242.9501a

\section{1. Введение}

Свойства металлических и металло-окисных наночастиц (НЧ) в полупроводниковых и прозрачных диэлектрических матрицах широко исследуются из-за перспективы их применения в современных приборах опто- и микроэлектроники [1]. НЧ оксида цинка играют важную роль, так как $\mathrm{ZnO}$ является прямозонным материалом с шириной запрещенной зоны 3.37 эВ и имеет большую энергию связи экситона 60 мэВ. Поэтому НЧ оксида цинка могут использоваться в светоизлучающих устройствах ультрафиолетового диапазона [3,4]. Благодаря другим уникальным свойствам ZnO, таким как сорбционный эффект, пьезоэлектричество и ферромагнетизм уже при комнатной температуре, они могут применяться в солнечных элементах [5], в газовых сенсорах [6], в устройствах спинтроники [7], в устрой- ствах памяти (мемристорах) [8], в медицине [9] и биологии [10].

Так как до настоящего времени в микроэлектронике преимущественно используется $\mathrm{Si}$, то наличие НЧ цинка и $\mathrm{ZnO}$ в подложке $\mathrm{Si}$ вызывают особый интерес. Процесс формирования таких НЧ с контролируемыми размерами и формой представляет значительную практическую ценность. Существует несколько попыток формирования наночастиц $\mathrm{Zn}$ и $\mathrm{ZnO}$ в $\mathrm{Si}$ путем имплантации $\mathrm{Zn}$ и последующего термического окисления имплантированных кремниевых пластин [11-13]. Ранее мы уже сообщали о наших исследованиях формирования наночастиц Zn и $\mathrm{ZnO}$ в подложках $\mathrm{Si}$, имплантированных ионами $\mathrm{Zn}$ при повышенных температурах с последующим отжигом в атмосфере кислорода [14]. В данной работе мы представляем результаты исследования формирования НЧ в подложках $\mathrm{Si}$, последовательно имплантированных $\mathrm{Zn}$ и О при повышенных температурах. 


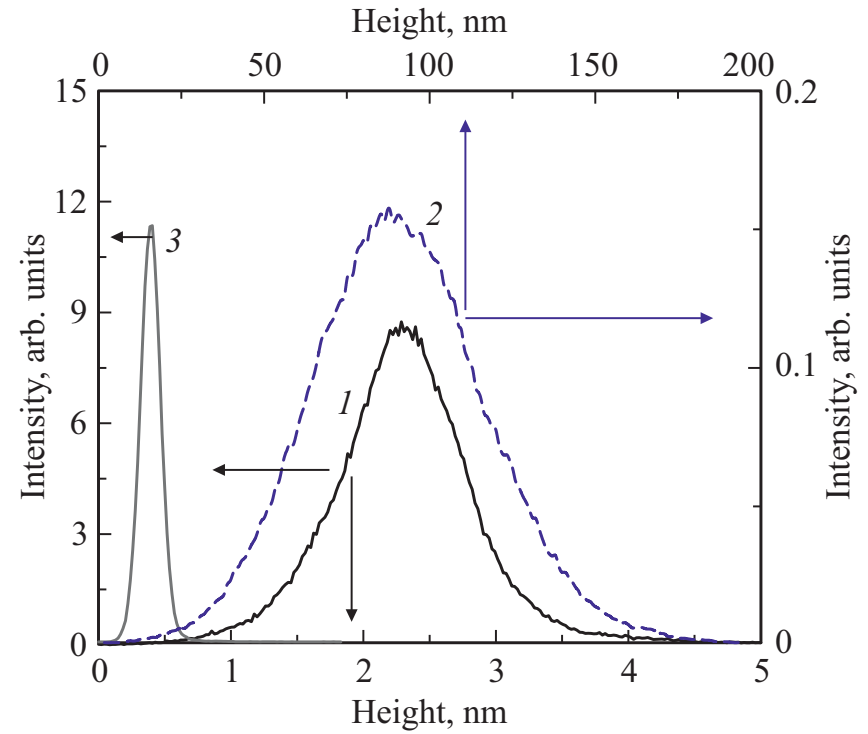

Рис. 1. Гистограммы шероховатости для исследуемых образцов: 1 - Si образца после $\mathrm{Zn} / \mathrm{O}$ имплантации, $2-\mathrm{Si}$ образца после фотонного отжига при эффективной температуре $700^{\circ} \mathrm{C}$, 3 - кремниевой подложки с естественным слоем $\mathrm{SiO}_{2}$.

\section{2. Образцы и методики эксперимента}

Выращенные методом Чохральского подложки $\mathrm{Si}$ $n$-типа с ориентацией (100) имплантировали вначале ионами ${ }^{64} \mathrm{Zn}^{+}$с дозой $5 \cdot 10^{16} \mathrm{~cm}^{-2}$ и энергией 50 кэВ, а затем ионами ${ }^{16} \mathrm{O}^{+}$с дозой $2 \cdot 10^{17} \mathrm{~cm}^{-2}$ и энергией 20 кэВ. На обоих этапах имплантации температура подложки составляла $\sim 350^{\circ} \mathrm{C}$. Затем подложки были разрезаны на образцы размером $10 \times 10$ мм, и эти образцы были подвергнуты изохронному (в течение 20 мин) фотонному отжигу в вакууме. На каждом этапе фотонного отжига эффективная температура составляла от 500 до $900^{\circ} \mathrm{C}$ с шагом $100^{\circ} \mathrm{C}$.

Топография образца изучалась с помощью сканирующей зондовой микроскопии (ACM) MFP-3D (Asylum Research) в полуконтактной атомно-силовой моде (АC Air Topography) и в Кельвин-моде. Профили имплантированных примесей $\mathrm{Zn}$ и $\mathrm{O}$, а также сопутствующих оксидных ионов, которые образовались в имплантированном образце при отжиге, изучали методом вторичноионной масс-спектрометрии с помощью времяпролетного масс-спектрометра ToF.SIMS 5-100 (ION-TOF). При послойном анализе распыление образцов осуществляли ионами $\mathrm{O}_{2}^{+}$с энергией $0-5$ кэВ при анализе положительных вторичных ионов $\mathrm{Si}, \mathrm{O}$ и $\mathrm{Zn}$ и ионами $\mathrm{Cs}^{+}$с энергией 0.5 кэВ при анализе отрицательных вторичных ионов $\mathrm{O}, \mathrm{Si}, \mathrm{SiO}, \mathrm{SiO}_{2}, \mathrm{ZnO}$ и $\mathrm{Zn}_{2} \mathrm{SiO}_{4}$. Энергия анализирующего пучка $\mathrm{Bi}^{+}$составляла 30 кэВ. Измерения фотолюминесценции (ФЛ) проводились при температуре $10 \mathrm{~K}$ по стандартной фазочувствительной методике с охлаждаемым германиевым фотосопротивлением в качестве детектора. ФЛ возбуждалась фотонами с длиной волны $\lambda=920$ нм при плотности возбуждения $10 \mathrm{MBT} / \mathrm{MM}^{2}$.

\section{3. Результаты и обсуждение}

\section{1. Сканирующая зондовая микроскопия}

У исходной $\mathrm{Si}-$ подложки поверхность достаточно гладкая и ее шероховатость составляет менее $0.1 \mathrm{Hм}$, а максимум распределения шероховатости составляет $\sim 0.5$ нм (рис. 1, кривая 3). На рис. 2, а представлено 2D ACM-изображение, а на рис. 2, $b$ показано 3D ACMизображение поверхности образцов подложек $\mathrm{Si}$ после $\mathrm{Zn} / \mathrm{O}$ горячей имплантации. На рис. 1 представлено распределение шероховатости по всему квадратному

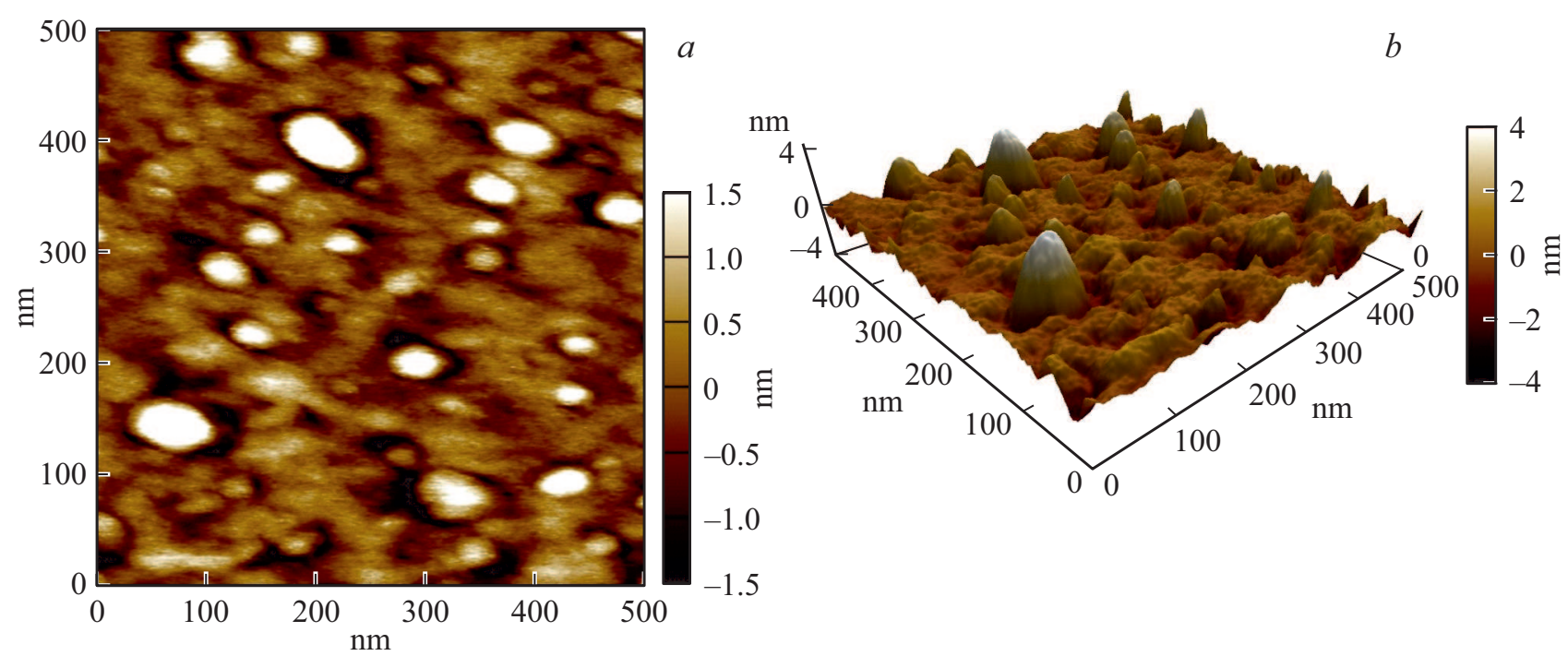

Рис. 2. 2D (a) и 3D (b) АCM-изображения поверхности $\mathrm{Si}$ образца после $\mathrm{Zn} / \mathrm{O}$ имплантации. 


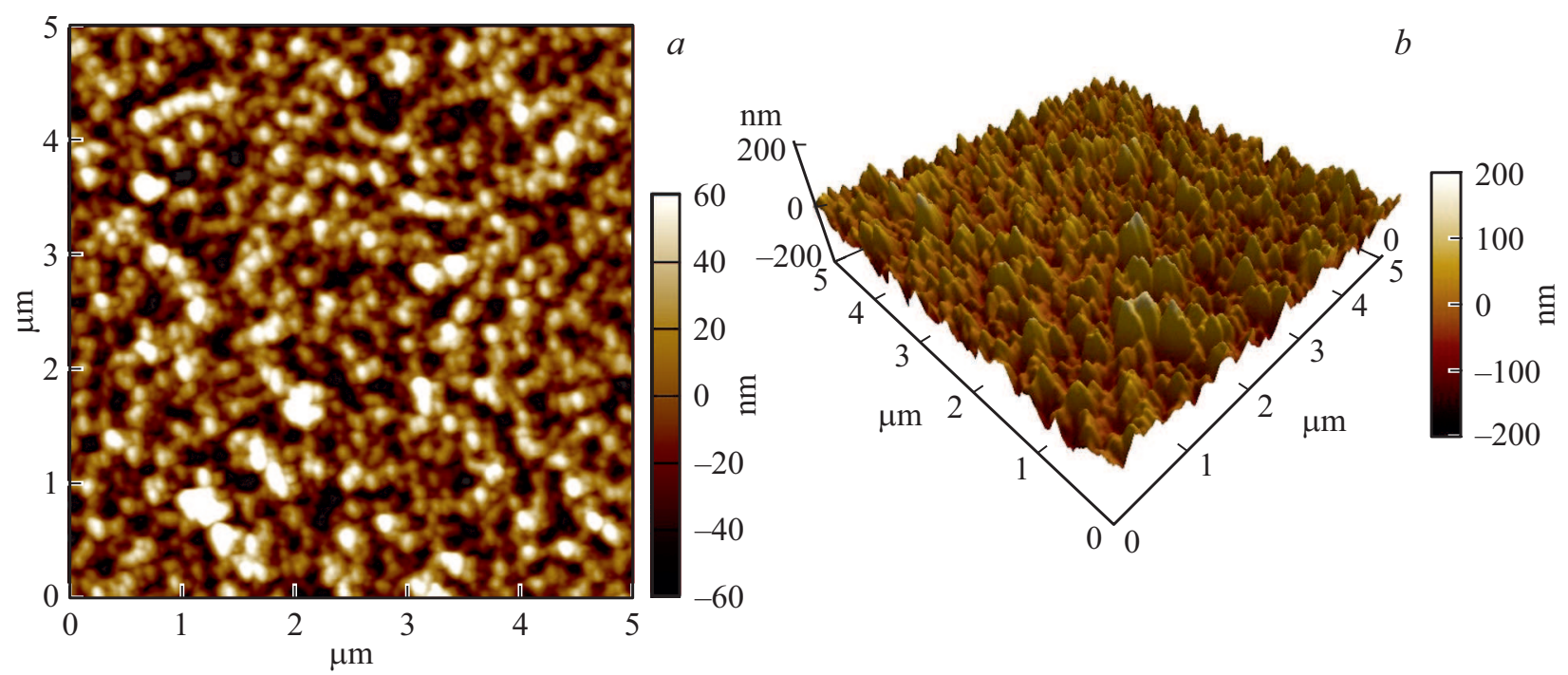

Рис. 3. 2D $(a)$ и 3D $(b)$ ACM-изображения поверхности $\mathrm{Si}$ образца после фотонного отжига при эффективной температуре $700^{\circ} \mathrm{C}$.

кадру для этого случая (кривая 1 ). Из анализа рис. 2 следует, что после горячей $\mathrm{Zn} / \mathrm{O}$ имплантации поверхность образца становится более неоднородной по сравнению с исходным состоянием до имплантации. Теперь параметры шероховатости: $\mathrm{Rms}=0.58 \mathrm{Hм}, \mathrm{Ra}=0.43 \mathrm{Hм}$, а максимум шероховатости составляет $2.3 \mathrm{Hм}$ (рис. 1, кривая 1). Поверхность состоит из бугорков и долин. Бугорки имеют круглую форму и размер в плоскости в диапазоне 20-50нм. Эти округлые бугорки окружены долинами с примерно таким же размером в плоскости (рис. 2). Наблюдаемые бугорки обусловлены $\mathrm{Zn}$-содержащими нанокластерами (преимущественно $\mathrm{Zn}$ и/или $\mathrm{ZnO}$ ) и радиационными дефектами (см. далее раздел ПЭМ), образовавшимися после имплантации.

На рис. 3, а представлено 2D АСМ-изображение поверхности образца после импульсного светового отжига в вакууме при эффективной температуре $700^{\circ} \mathrm{C}$. Распределение шероховатости по всему кадру для этого случая представлено на рис. 1 (кривая 2). Теперь параметры шероховатости: $\mathrm{Rms}=26 \mathrm{Hм}, \mathrm{Ra}=21 \mathrm{Hм}$. Видно, что после отжига поверхность образца становится более структурированной (рис. $3, b$ ), а, именно, ее шероховатость значительно увеличивается, так что ее средние значения достигают значения 90 нм (рис. 2, кривая 2). Поверхность состоит из бугорков и долин. Оба типа этих неровностей поверхности в плоскости имеют размеры $\sim 100$ нм. Образовавшиеся бугорки обусловлены $\mathrm{Zn}$-содержащими нанокластерами, состоящими преимущественно из фазы $\mathrm{ZnO}$ и (или) фазы $\mathrm{Zn}_{2} \mathrm{SiO}_{4}$, образовавшимися после фотонного отжига.

\section{2. Времяпролетная вторично-ионная масс-спектрометрия}

На рис. 4 представлены профили распределения по глубине образцов $\mathrm{Zn}$ (кривая 2) и О (кривая 1) сра- зу после имплантации, а также после отжига (кривая 4 для $\mathrm{Zn}$ и кривая 3 для О). Калибровка профилей концентрации $\mathrm{Zn}^{+}$и $\mathrm{O}^{-}$в образце после имплантации (кривая 2) проводилась в соответствии с известными дозами имплантации. Максимальная концентрация $\mathrm{Zn}$ находится на глубине 50 нм и соответствует $8.6 \cdot 10^{21} \mathrm{~cm}^{-3}$. Распределение имплантированного Zn имеет кроме главного максимума, о котором шла речь выше, еще и дополнительный приповерхностный максимум на глубине $\sim 5$ нм примерно такой же величины. Последнее может быть связано с сегрегацией цинка из-за наличия поверхностного слоя оксида кремния.

Что касается профиля имплантированного кислорода после $\mathrm{Zn} / \mathrm{O}$ имплантации, то максимальная концентра-

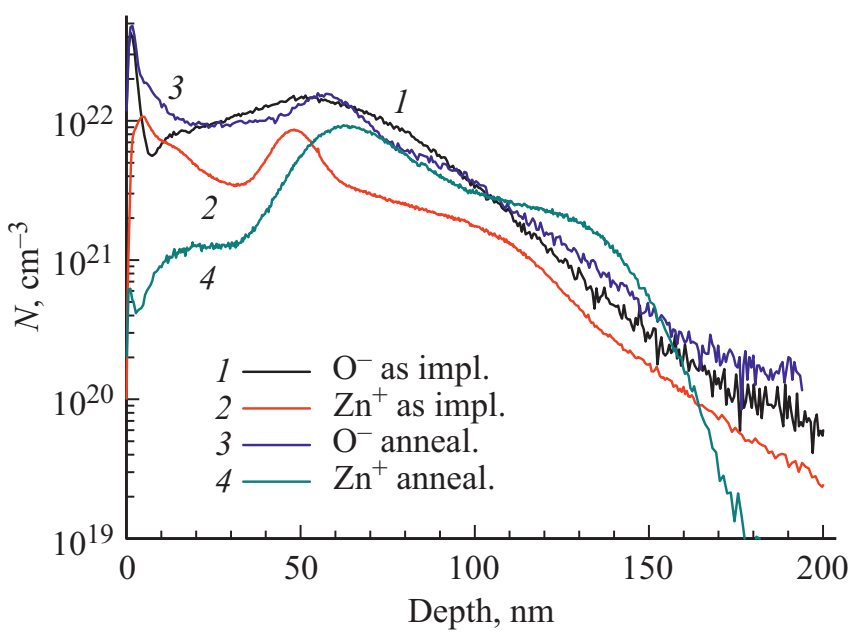

Рис. 4. Профили распределения $\mathrm{O}$ и $\mathrm{Zn}$ по глубине в исследуемых образцах: ионы $\mathrm{O}^{-}(1)$ и $\mathrm{Zn}^{+}(2)$ после имплантации; ионы $\mathrm{O}^{-}(3)$ и $\mathrm{Zn}^{+}$(4) после отжига образцов при эффективной температуре $700^{\circ} \mathrm{C}$. 


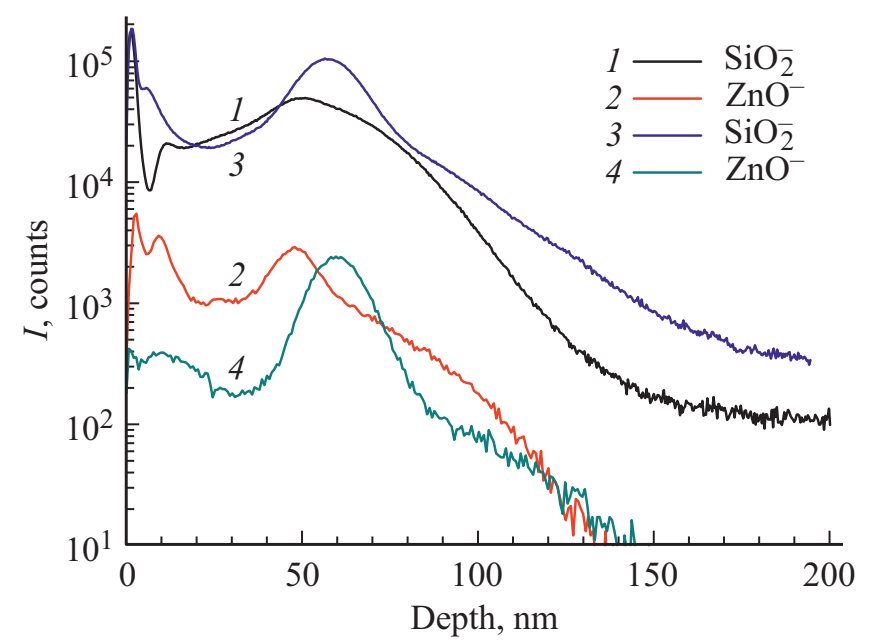

Рис. 5. Токи основных отрицательных ионов оксидов для $\mathrm{Zn} / \mathrm{O}$ имплантированных и отожженных при эффективной температуре $700^{\circ} \mathrm{C}$ образцов: ионы $\mathrm{SiO}_{2}^{-}$(1) и $\mathrm{ZnO}^{-}$(2) для имплантированных и ионы $\mathrm{SiO}_{2}^{-}$(3) и $\mathrm{ZnO}^{-}$(4) для отожженных образцов.

ция $\mathrm{O}^{-}$находится на глубине 55 нм и соответствует $1-2 \cdot 10^{22} \mathrm{~cm}^{-3}$. Однако распределение $\mathrm{O}^{-}$имеет кроме главного максимума, о котором шла речь выше, еще и дополнительный приповерхностный максимум на глубине $\sim 5$ нм величиной $4.5 \cdot 10^{22} \mathrm{~cm}^{-3}$. Это может быть связано с наличием естественного поверхностного слоя оксида кремния такой толщины. Следует отметить, что оба образца (кривые 1 и 2) имеют поверхностный слой толщиной от 5-10нм с высоким содержанием загрязнений углеводородными соединениями.

Профиль распределения концентрации $\mathrm{Zn}^{+}$по глубине образца после отжига при эффективной температуре $700^{\circ} \mathrm{C}$ показан на рис. 4 (кривая 4). Калибровка этого профиля по концентрации проводилась по коэффициенту относительной элементной чувствительности, рассчитанному в результате калибровки по концентрации профиля $\mathrm{Zn}$, показанной на рис. 4 (кривая 2). Максимум концентрации цинка после отжига сместился на глубину 65 нм и и практически не изменился по величине после $\mathrm{Zn} / \mathrm{O}$ имплантации. Пересчитанная доза внедренного $\mathrm{Zn}$ в этом образце составляет $1.5 \cdot 10^{16} \mathrm{~cm}^{-2}$, т.е. она уменьшилась в 3 раза по сравнению с имплантационной дозой. Распределение $\mathrm{Zn}$ после отжига имеет кроме главного максимума, о котором шла речь выше, еще и дополнительный поверхностный максимум величиной $4 \cdot 10^{20} \mathrm{~cm}^{-3}$, что более, чем на порядок меньше по сравнению с главным. Такое уменьшение поверхностного максимума $\mathrm{Zn}$ связано с удалением углеводородных соединений при отжиге.

На рис. 5 показаны профили по глубине образца для токов основных отрицательных ионов оксидов при распылении подложки ионами $\mathrm{Cs}^{+}$с энергией 0.5 кэВ. Эти профили качественно соответствуют концентрационным профилям как для ионов $\mathrm{SiO}_{2}^{-}$(кривая 1) и $\mathrm{ZnO}^{-}$(кривая 2) для образцов после $\mathrm{Zn} / \mathrm{O}$ имплантации, так и для ионов $\mathrm{SiO}_{2}^{-}$(кривая 3) и $\mathrm{ZnO}^{-}$(кривая 4) для образцов после импульсного фотонного отжига при эффективной температуре $700^{\circ} \mathrm{C}$ соответственно. Профиль тока ионов $\mathrm{ZnO}$ после $\mathrm{Zn} / \mathrm{O}$ имплантации имеет главный максимум на глубине 50 нм, что соответствует главному максимумy $\mathrm{Zn}$ после имплантации. Профиль распределения тока $\mathrm{ZnO}^{-}$, имплантированного $\mathrm{Zn}$, имеет, кроме главного максимума, дополнительный приповерхностный максимум в виде дублета на глубине $5-15$ нм в $2-3$ раза больше, чем главный максимум. Как уже было отмечено выше, это может быть связано как с сегрегацией $\mathrm{ZnO}$ из-за наличия поверхностного слоя оксида кремния, так и с присутствием поверхностных углеводородных загрязнений.

Что касается профиля тока для ионов $\mathrm{SiO}_{2}^{-}$после $\mathrm{Zn} / \mathrm{O}$ имплантации, то его максимум (см. рис. 5, кривая 1) находится на глубине 55 нм, что соответствует максимуму имплантированного кислорода. Очевидно, что распределение ионов $\mathrm{SiO}_{2}^{-}$имеет, кроме главного максимума, и приповерхностный максимум на глубине $\sim 5$ нм, обусловленный наличием естественного поверхностного слоя оксида кремния.

После импульсного фотонного отжига при эффективной температуре $700^{\circ} \mathrm{C}$ оба рассмотренных выше профиля изменяются. Их главные максимумы смещаются внутрь образца на глубину 60 нм. Главный максимум распределения $\mathrm{ZnO}^{-}$почти не изменяется по величине, а его приповерхностный максимум становится чисто поверхностным и уменьшается на порядок величины.

Профиль $\mathrm{SiO}_{2}$ после фотонного отжига имеет следующие особенности: его главный максимум увеличивается, а приповерхностный не изменяется ни по величине, ни по положению. Это и очевидно, так как пленка естественного поверхностного слоя оксида кремния остается на месте.

\section{3. Просвечивающая электронная микроскопия}

На рис. 6 показаны обзорные ПЭМ изображения приповерхностного слоя поперечного сечения образца после $\mathrm{Zn} / \mathrm{O}$ имплантации для двух увеличений. При холодной имплантации распределение имплантированного $\mathrm{Zn}$ при энергии внедрения 50 кэВ имеет максимальную концентрацию на глубине прогнозируемого диапазона $R_{p}=38.4 \mathrm{Hм}$, а распределение имплантированного О при энергии внедрения 20 кэВ имеет максимальную концентрацию на глубине прогнозируемого диапазона $R_{p}=40.0$ нм согласно расчетам по программе SRIM [16]. На вставке к рис. 6, $a$ представлена электронограмма по всему кадру. На рис. $6, a$ область имплантации $\mathrm{Zn}$ отчетливо видна в середине ПЭМ изображения, где по изменению контраста изображения можно выявить Zn-содержащие кластеры и радиационные 
$a$

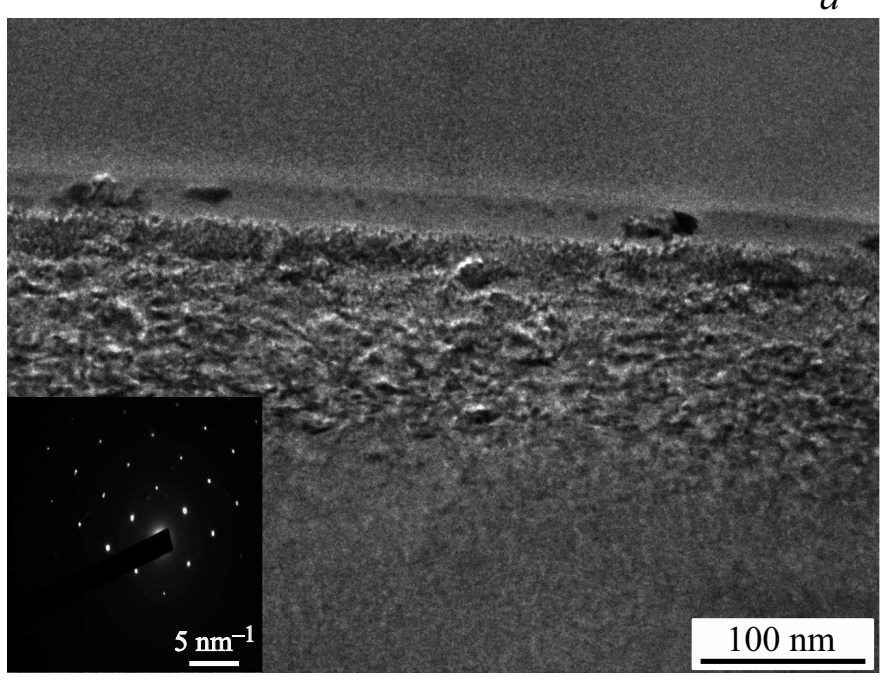

$b$

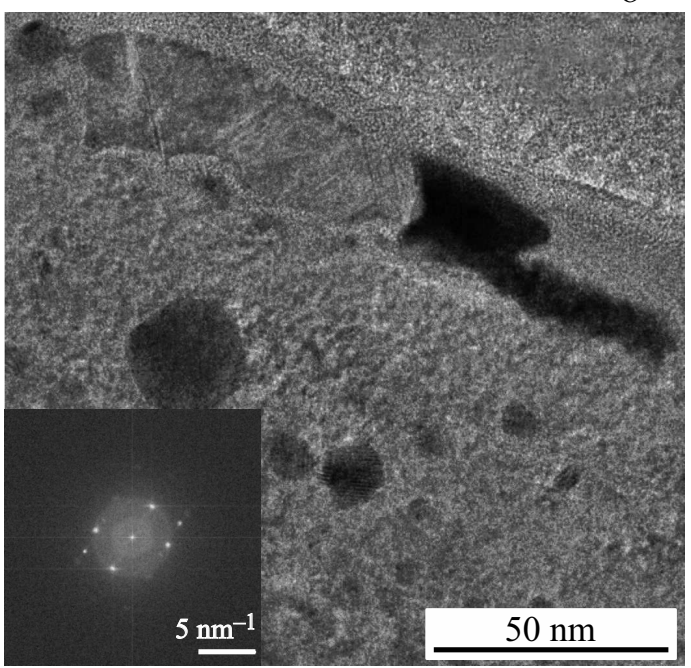

Рис. 6. Обзорные ПЭМ-изображения поперечного сечения приповерхностного слоя образца после $\mathrm{Zn} / \mathrm{O}$ имплантации с разными степенями увеличения $(a)$ и $(b)$. На вставке представлены электронограммы. [Электоронограмма для рис. $6, b$ приложена отдельно.]

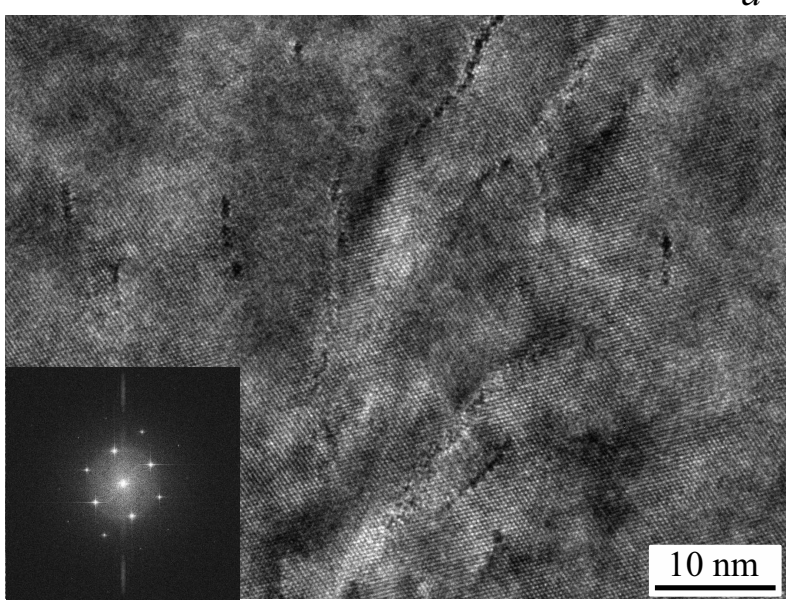

$b$

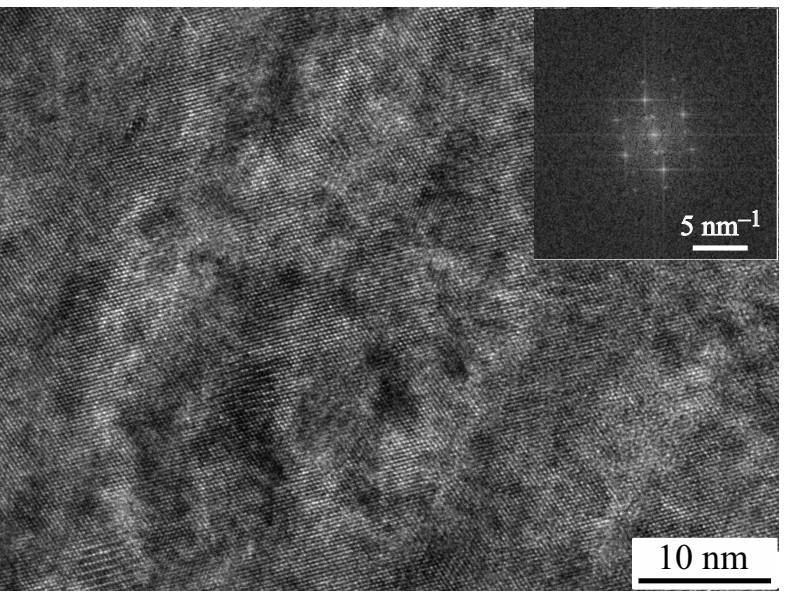

Рис. 7. ПЭМ ВР-изображения поперечного сечения приповерхностного слоя образца после $\mathrm{Zn} / \mathrm{O}$ имплантации с разными степенями увеличения: $a-$ изображение с дислокациями, на вставке представлен фурье-образ по кадру; $b-$ изображение с муаровыми пятнами, на вставке представлен фурье-образ по кадру.

дефекты. Из анализа рефлексов на электронограмме на вставке к рис. 6, $a$ можно заключить, что в подложке $\mathrm{Si}$ после имплантации образовались двойники. Отражения от двойников смещены на одну треть относительно основных рефлексов и, как и ожидается, имеют меньшую яркость, Поперечное сечение обратной решетки слегка отображается вне оси зоны.

На рис. 6, $b$ на обзорном ПЭМ изображении с большим увеличением видны пятна круглой формы, представляющие собой Zn-содержащие кластеры. Аморфное состояние этих кластеров подтверждается фурьеобразом по всему кадру (см. вставку на этом рисунке), на котором отсутствуют следы кристаллографических плоскостей. На этом фурье-образе имеется гало, указы- вающее на частично аморфное состояние подложки $\mathrm{Si}$ после $\mathrm{Zn} / \mathrm{O}$ имплантации.

На рис. 7 представлены два разных ПЭМ ВР изображения в середине зоны имплантации для образца после $\mathrm{Zn} / \mathrm{O}$ ионной имплантации. На рис. 7, $a$ представлено ПЭМ ВР изображение, на котором видны участки дислокаций размером $\sim 10$ нм. На вставке к рис. 7, $a$ представлен фурье-образ по всему кадру, из которого следует, что дислокации находятся в кремниевой подложке. На рис. 7, $b$ представлено ПЭМ ВР изображение приповерхностного слоя, на котором видны муаровые пятна размером $\sim 20$ нм. На вставке к рис. 7, $b$ представлен фурьеобраз по всему кадру. Из него следует, что муаровые пятна обусловлены наложением одинаковых слоев с раз- 


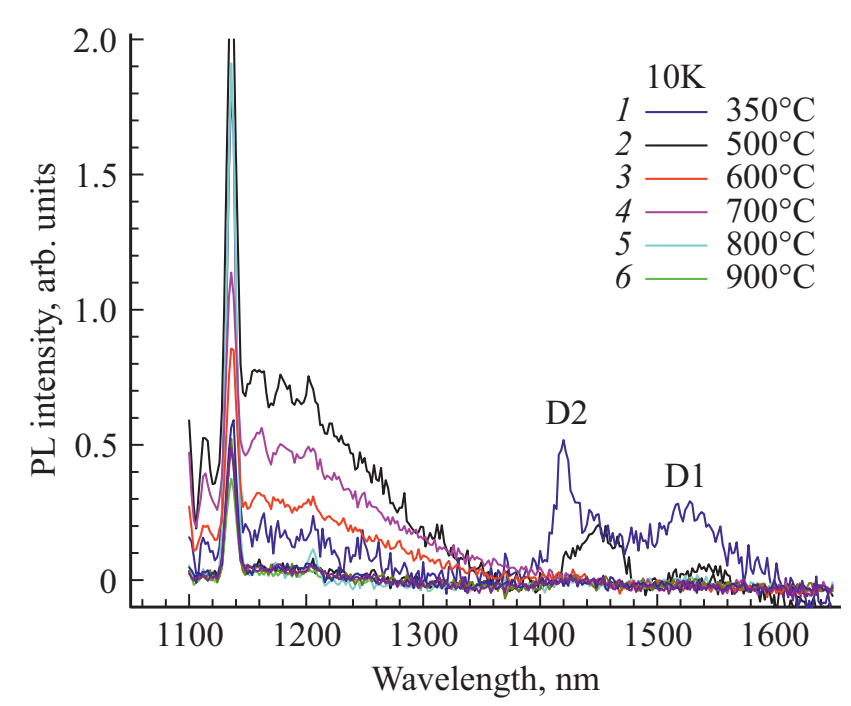

Рис. 8. Спектры ФЛ в ИК-области при $10 \mathrm{~K}$ (интенсивность кривых 1 и 2 увеличена в 3 раза для наглядности).

ной ориентацией и/или расстоянием между плоскостями в кристаллической решетке кремниевой матрицы.

\section{4. Фотолюминесценция}

На рис. 8 представлены спектры фотолюминесценции (ФЛ) исследуемых образцов в ближней ИК-области при температуре $10 \mathrm{~K}$. После $\mathrm{Zn} / \mathrm{O}$ имплантации спектр ФЛ (кривая 1) демонстрирует наличие характерной дислокационной люминесценции (ДЛ) в кремнии. Это однозначно свидетельствует о наличии значительной плотности дислокаций в кремнии после его облучения ионами $\mathrm{Zn}$ и О, что согласуется с данными ПЭМ ВР (рис. 7,a). Как известно, ДЛ в кремнии представляет собой серию полос D1-D4 в интервале энергий 0.8-1 эВ [18]. Как следует из анализа кривой 1 на рис. 8, в спектре ФЛ практически отсутствует коротковолновая часть ДЛ, состоящая из линий D4 (1245 нм) и ее фононного повторения D3 (1325 нм). Так как линии D3 и D4 связаны с рекомбинацией носителей заряда на прямолинейных участках расщепленных 60-градусных дислокаций [19-21], то отсутствие в спектре данных линий люминесценции свидетельствует о соответствующей морфологии дислокаций, образовавшихся после $\mathrm{Zn} / \mathrm{O}$ облучения кремния. В то же время в спектре люминесценции доминирует длинноволновая часть ДЛ, состоящая из линий D1 $(1530$ нм) и D2 (1420 нм), источниками которых являются некие структурные дефекты в ядре дислокации.

Последующий отжиг образцов при температуре $500^{\circ} \mathrm{C}$ приводит к сильному гашению интенсивности ДЛ и одновременному появлению широкой бесструктурной полосы с центром $\sim 1.07$ эВ, сохраняющейся вплоть до отжига при $700^{\circ} \mathrm{C}$. Природа данных излучающих центров на данный момент неизвестна. Предположительно, ответственными за них являются дефекты в объеме кремния, образующиеся при отжиге из радиационных дефектов. Образовавшиеся излучательные центры являются конкурирующими каналами рекомбинации по отношению к дислокациям, что является одной из причин гашения ДЛ. Кроме этого, в процессе отжигов при более высоких температурах может происходить аннигиляция дислокаций, образовавшихся на более низкотемпературной стадии имплантации, что также приводит к гашению ДЛ. Дальнейший отжиг образцов при температурах $800^{\circ} \mathrm{C}$ и выше приводит к исчезновению полосы люминесценции с центром 1160 нм и значительному увеличению интенсивности экситонной люминесценции, что свидетельствует о существенном снижении количества центров рекомбинации в объеме кремния вследствие их отжига.

\section{4. Заключение}

Из полученных результатов можно сделать следующие выводы.

1. Подложки $n$-типа CZ Si с ориентацией (100) были имплантированы при температуре $350{ }^{\circ} \mathrm{C}$ ионами ${ }^{64} \mathrm{Zn}^{+}$ с дозой $5 \cdot 10^{16} \mathrm{~cm}^{-2}$ и энергией 50 кэВ, а затем ионами ${ }^{16} \mathrm{O}^{+}$с дозой $2 \cdot 10^{17} \mathrm{~cm}^{-2}$ и энергией 20 кэВ.

2. После $\mathrm{Zn} / \mathrm{O}$ имплантации в приповерхностном слое образуются радиационные дефекты: точечные дефекты и их кластеры, двойниковые зерна, дислокации, а также $\mathrm{Zn}$-содержащие кластеры (преимущественно состава Zn и $\mathrm{ZnO})$ со средними размерами 10-20 нм и со средними размерами 20-50 нм на поверхности $\mathrm{Si}$-подложки.

3. По мере отжига происходит постепенный отжиг радиационных дефектов, а после отжига при эффективной температуре $700^{\circ} \mathrm{C}$ в приповерхностном слое и на поверхности $\mathrm{Si}$-подложки выявлены $\mathrm{Zn}$-содержащие кластеры (преимущественно состава $\mathrm{ZnO}$ ) с размером $\sim 100$ нм.

\section{Финансирование работы}

Работа частично выполнена в рамках государственного задания Федерального государственного учреждения „Федеральный научный центр Научно-исследовательский институт системных исследований Российской академии наук“ № 0065-2019-0003(ААА-А19119011590090-2). Работа также частично финансировалась в рамках государственного задания Федерального государственного бюджетного учреждения науки „Физико-технологический институт им. К.А. Валиева Российской академии наук“ и Федерального государственного бюджетного учреждения науки Института физики твердого тела Российской академии наук, а также Министерством науки и высшего образования России для Национального исследовательского технологического университета „Московский институт стали и сплавов“ (проект № 0718-2020-0031). 


\section{Конфликт интересов}

Авторы заявляют, что у них нет конфликта интересов.

\section{Список литературы}

[1] Nanoclusters and Nanocrystals, H. Singh Nalwa (ed.) (Hitachi, Japan, 2003).

[2] C. Flytzanis, F. Haqche, M.C. Klein, D. Ricard, Ph. Roussignol. In Prog.Optics, E.Wolf (ed.), (North Holland, Amsterdam, 1999) p. 29, 321.

[3] S. Chu, M. Olmedo, Zh. Yang, J. Kong, J. Liu etal. Appl. Phys. Lett., 93, 181106 (2008).

[4] C.Y. Jiang, X.W. Sun, G.Q. Lo, D.L. Kwong, J.X. Wang. Appl. Phys. Lett., 90, 263501 (2007).

[5] G.P. Smestad, M. Gratzel. J. Chem. Educ., 75, 752 (1998).

[6] C. Li, Y. Yang, X.W. Sun, W. Lei, X.B. Zhang, B.P. Wang, J.X. Wang, B.K. Tay, J.D. Ye, G.Q. Lo, D.L. Kwong. Nanotechnology, 18, 135604 (2007).

[7] B.B. Straumal, A.A. Mazilkin, S.G. Protasova, A.A. Myatiev, P.B. Straumal, G. Schütz, P.A. van Aken, E. Goering, B. Baretzky. Phys. Rev. B, 79, 205206 (2009).

[8] J.S. Dodds1, F.N. Meyers, K.J. Loh. Smart Structures and Systems, 12, 055 (2013).

[9] A. Sirelkhatim, S. Mahmud, A. Seeni, N.H.M. Kaus, L.C. Ann, S.K. ohd Bakhori, H. Hasan, D. Mohamad. Nano-Micro Lett., 7, 219 (2015).

[10] S. Inbasekaran, R. Senthil, G. Ramamurthy, T.P. Sastry. Intern. J. Innov // Res. Sci. Eng. Technol., 3, 8601 (2014).

[11] H. Amekura, Y. Takeda, N. Kishimoto. Mater. Lett., 222, 96 (2011).

[12] Y.Y. Shen, X.D. Zhang, D.C. Zhang, Y.H. Xue, L.H. Zhang, C.L. Liu. Mater. Lett., 65, 2966 (2011).

[13] V. Privezentsev, V. Kulikauskas, E. Steinman, A. Bazhenov. Phys. Status Solidi C, 10, 48 (2013).

[14] V.V. Privezentsev, V.S. Kulikauskas, V.V. Zatekin, D.V. Petrov, A.Yu. Trifonov, A.A. Batrakov. J. Surface Investigation. $X$-ray, Synchrotron and Neutron Techniques, 9 (3), 486 (2015).

[16] J.F. Ziegler, J.P. Biersack. SRIM 2013 (http://www.srim.org).

[17] G. Ledoux, J. Gong, F. Huisken, O. Guillois, C. Reynaud. Appl. Phys. Lett., 80, 4834 (2002).

[18] Н.А. Дроздов, А.А. Патрин, В.Д. Ткачев. Письма ЖЭТФ, 23 (11), 651 (1976).

[19] E.A. Steinman, V.I. Vdovin, T.G. Yugova, V.S. Avrutin, N.F. Izyumskaya. Semicond. Sci. Technol., 14, 582 (1999).

[20] R. Sauer, Ch. Kisielowski-Kemmerich, H. Alexander. Phys. Rev. Lett., 57, 1472 (1986).

[21] A.N. Izotov, A.I. Kolyubakin, S.A. Shevchenko, E.A. Steinman. Phys. Status Solidi A, 130, 193 (1992).

\section{Structure, Content and Properties of $\mathbf{Z n}$ and $\mathbf{O}$ Ion Hot Implanted Silicon}

V.V. Privezentsev ${ }^{1,2}$, A.P. Sergeev ${ }^{1}$, V.S. Kulikauskas ${ }^{3}$, D.A. Kiselev ${ }^{4}$, A.Yu. Trifonov ${ }^{5,6}$, A.N. Tereshchenko ${ }^{7}$

${ }^{1}$ FRC „Scientific Research Institute of System Analysis of the Russian Academy of Sciences",

117218 Moscow, Russia

${ }^{2}$ Valiev Institute of Physics \& Technology

of the Russian Academy of Sciences,

117218 Moscow, Russia

${ }^{3}$ Skobeltsyn Institute of Nuclear Physics,

Lomonosov Moscow State University,

119991 Moscow, Russia

${ }^{4}$ National University of Science and Technology

"MISiS“,

119049 Moscow, Russia

${ }^{5}$ National Research University "MIET", 124432 Moscow, Zelenograd, Russia

${ }^{6}$ Lukin Scientific Research Institute

of Physical Problem,

124432 Moscow, Zelenograd, Russia

${ }^{7}$ Institute of Solid-State Physics,

Russian Academy of Sciences,

142432 Chernogolovka, Moscow district, Russia

Abstract The Czochralski growth $\mathrm{Si}(100)$ substrates were implantation by ${ }^{64} \mathrm{Zn}^{+}$ions with dose of $5 \cdot 10^{16} \mathrm{~cm}^{-2}$ and energy of $50 \mathrm{keV}$ and then by the ${ }^{16} \mathrm{O}^{+}$ions with dose of $2 \cdot 10^{17} \mathrm{~cm}^{-2}$ and energy of $20 \mathrm{keV}$. During implantation the substrate temperature was about $350^{\circ} \mathrm{C}$. Then, the substrates were cut into $10 \times 10 \mathrm{~mm}$ samples, and were subjected to isochronous (for $20 \mathrm{~min}$ ) photonic annealing in vacuum. At each stage of photon annealing, the effective temperature was varied from 500 up to $900^{\circ} \mathrm{C}$ with a step of $100^{\circ} \mathrm{C}$. After implantation the radiation-induced point defects and their clusters are formed in the subsurface layer, twin grains, dislocations, as well as $\mathrm{Zn}$-containing clusters (mainly of $\mathrm{Zn}$ and $\mathrm{ZnO}$ composition) with an average size of $10-20 \mathrm{~nm}$ and an average size of $20-50 \mathrm{~nm}$ on Si substrate surface. As the annealing proceeds, the radiation defects gradually disappear, and after annealing at an effective temperature of $700^{\circ} \mathrm{C}$ the $\mathrm{Zn}$-containing clusters (presumably consisted of $\mathrm{ZnO}$ phase and particularly of $\mathrm{Zn}_{2} \mathrm{SiO}_{4}$ phase) with a size of about $100 \mathrm{~nm}$ are revealed in the surface layer and on the Si substrate surface.

Редактор А.Н. Смирнов 